\title{
Repeated Complication Following Atlantoaxial Fusion: A Case Report
}

\author{
Chang Hyun Oh${ }^{1}$, Gyu Yeul $\mathrm{Ji}^{1}$, Hyun Sung Seo ${ }^{2}$, Seung Hwan Yoon ${ }^{2}$, \\ Dongkeun Hyun ${ }^{2}$, Hyeong-Chun Park ${ }^{2}$

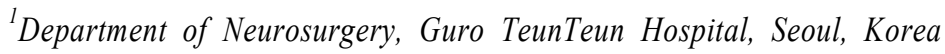 \\ ${ }^{2}$ Department of Neurosurgery, Inha University School of Medicine, Incheon, Korea
}

\begin{abstract}
A patients with atlantoaixial instability and osodontoideum underwent atlantoaixial fusion (Harms and Melcher technique) with demineralized bone matrix. But, unfortunately, the both pedicle screws in C2 were fractured within 9 weeks follow-up periods after several suspected episode of neck hyper-flexion. Fractured screws were not contact to occipital bone in several imaging studies, but it could irritate the occipital bone when neck extension because the relatively close distance between the occipital bone and $\mathrm{C} 1$ posterior arch. The patient underwent revision operation with translaminar screw fixation with autologus iliac bone graft. Postsurgical course were uneventful except donor site pain, but the bony fusion was not satisfied after 4 months follow-up. The patient re-underwent revision operation in other hospital. Continuous complication after atlantoaixial fusion is rare, but the clinical course could be unlucky to patients. Postoperative immobilization could be important to prevent the unintended clinical course of patients.
\end{abstract}

Key Words: Atlantoaxial fusion $\cdot$ Cervical spine $\cdot$ Transpedicle screw $\cdot$ Pedicle screw fracture $\cdot$ Bone fusion $\cdot$ Complication

\section{INTRODUCTION}

Various pathological conditions such as os odontoideum, rotatorysubluxation, dens fracture or trauma, rheumatoid arthritis, and congenital or acquired ligamentous instability can affect the atlantoaxial instability ${ }^{1)}$. Various techniques of atlantoaxial stabilisation have been described in the literature. Gallie reported atlantoaxial arthrodesis by posterior wiring and autologous grafting ${ }^{9}$, and Magerl and Seeman introduced the C1-C2 transarticular screw fixation ${ }^{16}$. However, this technique is technically demanding and requires precise radiological and intraoperative knowledge of the localization of the vertebral artery to minimize the risk of iatrogenic damage. Goel et al. described the $\mathrm{C} 1$ lateral mass screws/C2 pedicle screws and plates technique ${ }^{11)}$. They reported that the procedure is technically demanding and that anexact three-dimensional understanding of the anatomy of the region and of the vertebral artery is important. Modern atlantoaxial instrumentation techniques are transpedicle screws and screw-rod constructs which is modified by Harms and Melcher ${ }^{17,21)}$. In contrast to the

- Received: June 18, 2013 • Revised: March 14, 2014

- Accepted: March 17, 2014

Corresponding Author: Seung Hwan Yoon, MD, PhD

Department of Neurosurgery, College of Medicine, Inha University,

27 Inhang-ro, Jung-gu, Incheon 400-711, Korea

Tel: +82-32-890-2370, Fax: +82-32-890-2374

E-mail: nsyoon@gmail.com relatively high rate of nonunion with wiring techniques, the rates of successful fusion with modern instrumentation and techniques exceed $95 \%{ }^{5}$. Biomechanical studies showed a construct stability of screw-rod constructs similar to transarticular screws $^{8,14)}$. So, some authors suggested that spine surgeons should reconsidered the use of bracing for C1-2 fusion procedures where rigid segmental fixation has been achieved ${ }^{4}$. Although they concluded the external cervical orthoses may be not necessary with Class III evidence ${ }^{4)}$, cervical collars were effective to provide an optimal environment for bone fusion by restrict the range of neck movement. Herein, this article reported a two-times unlucky case of pedicle screws fracture after atlantoaixial fusion with several episode of neck hyperflexion, and emphasized the limitation of neck movement after cervical posterior fixation.

\section{CASE REPORTS}

Forty three years-old man who complained persistent neck pain and whole body tingling sensation was visit the neurosurgical clinic to treatment. He was an orthopedic surgeon, and self-diagnosed his symptom as os odontoideum with atlantoaxial instability. The imaging studies were corrleated with his self diagnosis (Fig. 1). The operation was recommended to this patients, and proceeded after a week because he should stop the cardiovascular medication which was continued after cardiac stent insertion. 

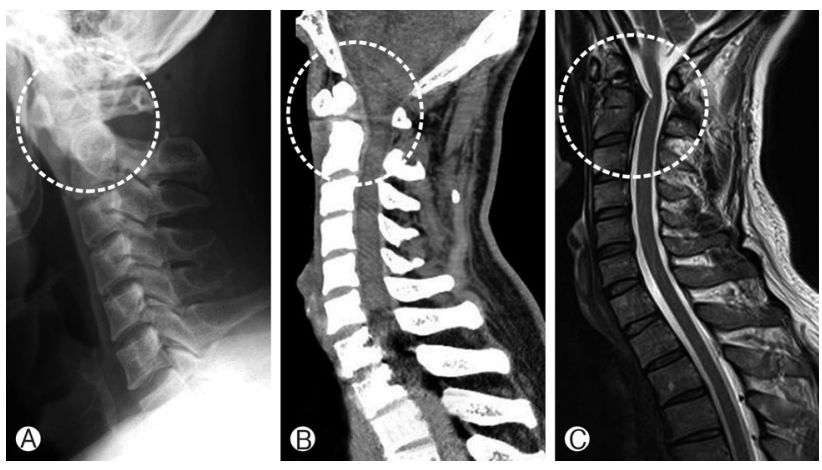

Fig. 1. Preoperative radiographic studies with atlantoaixial instability and osodontoideum were shown (white dot circle). The relatively close distance between the occipital bone and $\mathrm{Cl}$ posterior arch were suspected. (A) simple radiograph; (B) computed tomography; and $(C)$ magnetic resonance image.
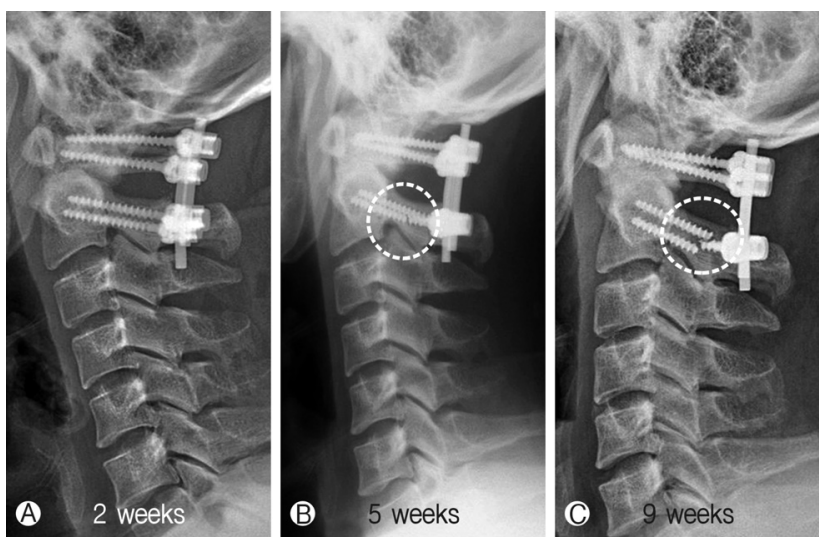

Fig. 2. Serial radiographs in 2, 5 and 9 weeks after first operation were showed serial C2 treanspedicel screws fracture (white dot circle). (A) 2 weeks; (B) 5 weeks; and (C) 9 weeks after posterior fusion.

The operation using Harms and Melcher methods was applied $^{17,21)}$. Skull traction was applied in the prone position after general anesthesia with endotracheal intubation was done. Gentle manipulation of the neck through the traction device was used under fluoroscopic control in an attempt to obtain reduction. The posterior elements of the vertebrae C1-C4 were freed by subperiosteal dissection through a standard posterior midline approach. Posterior C1 lateral mass screws, C2 pedicle screws, and screw-rod constructs were applied to the patient, and $3 \mathrm{~mL}$ of demineralized bone matrix (DBM) was applied to the C1-C2 area after decortications. Finally, the wound was closed in layers over a subcutaneous drain. During the operation any event was not happen, and the patient was improved immediately after the operation. The clinicians recommended the Philadelphia brace until at least 2 months after operation to provide an optimal environment for bone fusion

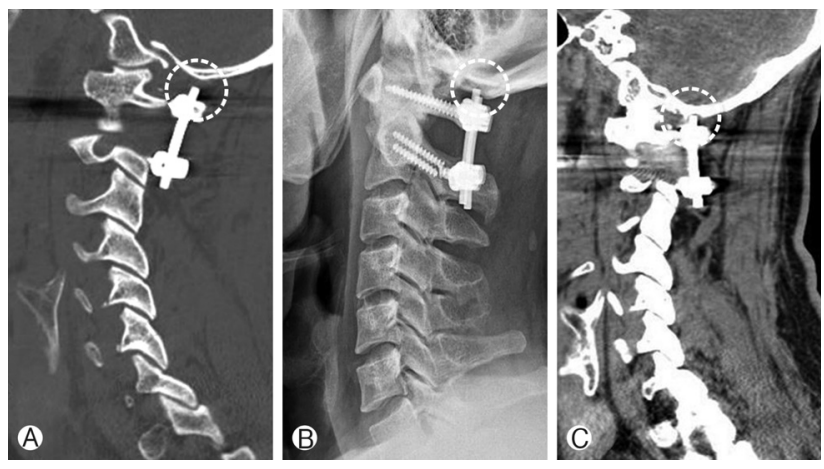

Fig. 3. Serial images showed mild erosion in occipital bone inferior cortex by rod construct which is not directly contact in normal position, but could irritate when it motioned after the screw fractures were happen (block dot circle). (A) computed tomography before the screws fracture; (B) simple radiograph after screws fracture; and $(C)$ computed tomography after the screws fracture.

by restrict the range of neck movement. But, unfortunately, the patines did not followed the instructions.

The first unlucky complications were happen within 9 weeks after the operation. Simple radiographs were checked during follow-up periods, and a screw fracture in $\mathrm{C} 2$ level was observed after 5 weeks after the operation (Fig. 2). The clinician did not undergo the revision operation, because the specific symptom related to the screw fracture was not observed. Postoperative neck immobilization was emphasized to patient once more, and closed follow-up was planned. But, the unilateral fixation of cervical spine did not achieve the desired clinical course, and the remnant $\mathrm{C} 2$ screw was also broken after 9 weeks after the operation (Fig. 2). Indeed, he complained posterior occipital pain during neck motion. Cervical computed tomography (CT) showed mild erosion in occipital bone inferior cortex by rod construct which is not directly contact in normal position, but could irritate when it motioned (Fig. 3). Irritation of fractured screws to the occipital bone could be happened by the relatively close distance between the occipital bone and $\mathrm{C} 1$ posterior arch in preoperative image studies (Fig. 1).

Finally, after several conversations with the patient, the patient had undergone the revision operation in 26 weeks after operation. The revision operation was done using translaminar screw fixation without removal of fractured screws because it was nearly impossible to remove it without destruction of C2 bony structures (Fig. 4). Longer C1 lateral mass screw was also applied to benefit the structural stabilization. Indeed, the autologous morselized bone grafts were obtained from the posterior iliac crest, and applied to the C1-C2 area after decortication. The postoperative course was also uneventful except the donor site pain. But, he complained sustained neck pain in 4 months after second operation, and non-union was suspected simple radiographs. Checked CT revealed scant bony 

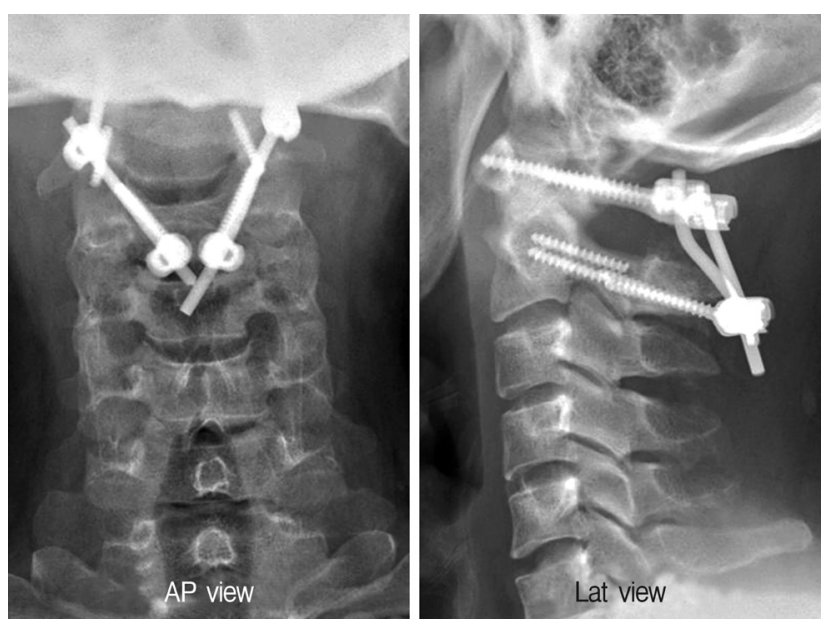

Fig. 4. The revision operation performed using longer $\mathrm{Cl}$ lateral mass screws and C2 translaminar screws fixation to stabilize the atlantoaxial instability after transpedicle screw fractures. The fractured particles were observed.

union at operated cervical level, but cervical instability was not suspected in radiographs (Fig. 4). After this second unlucky complication, the patient was admitted to other university hospital and undergone the third operation for non-union of atlantoaixial lesion.

\section{DISCUSSION}

Complications associated with craniocervical fusion surgery were analyzed by Lall et al. ${ }^{15}$. In this reports, 22 reports described data derived from 2,274 procedures were included, and the most commonly encountered perioperative complications were related to instrumentation failure after nonunion with rates as high as 7\% during occipitocervical fusion and 6.7\% during atlantoaxial fusion. Other commonly encountered complications included injury to the vertebral artery with $1.3-4.1 \%$ incidence during placement of C1-C2 transarticular screws, dural tears, and wound infection. The screw breakout was observed 10 cases $(0.7 \%)$ of 1,530 among C1-C2 transarticular screw, lateral mass screw, and pedicle screw complications ${ }^{6,12,15,18)}$. But, the screw fracture after transpedicle screws and screw-rod constructs is very rare with no relevant article in the literature review. Indeed, additional surgical procedure not related small aneurysm and non-union after atlantoaixial fusion is not well documented. Herein, the authors concentrically reviewed the complicated two-times unlucky case, and emphasized the importance of postoperative immobilization to prevent the unintended clinical course of patients.

Fixation of the atlantoaxial complex using polyaxial-head screws and screw-rod constructs seems to be a reliable techni-

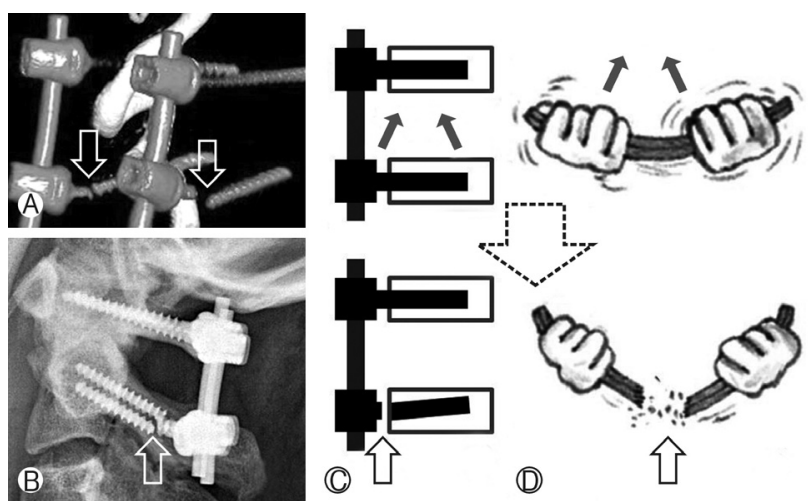

Fig. 5. The cannulated screws were pointed to cephalad trajectory and fractured tip close to screw head was pointed to caudal trajectory, and it meaned the dynamic forces contributing the screw fracture were derived from hyperflexion of neck motion as the illustration indicated. (A) reconstructed screw image; (B) simple radiography; $(C)$ the illustrated force contributing the screws fracture; and (D) the illustration to better understanding.

que and should be considered an efficient alternative to the previously reported techniques ${ }^{13)}$. The polyaxial screws are incorporated as part of amodular system for fusions to atlantoaxialcervical spine.

This technique avoids damage to the C1-C2 facet joint and thus can be used in patients who require an open reduction maneuver followed by temporary limited fixation ${ }^{13)}$. But, this construct system is not perfect technique as this case presented, although the biomechanical properties of this construct are similar to transarticular screws ${ }^{8,14)}$.

Both transpedicle screws and screw-rod constructs modified by Harms and Melcher at C2 level was fractured within 9 weeks after the first operation (first screw fracture was happen in 5 weeks after the operation). The postoperative radiographs showed normal alignment of atlantoaxial spine, but displacement of atlantoaxial spine aligment was observed after sequential screw fractures (Fig. 2). The cannulated screws were pointed to cephalad trajectory and fractured tip close to screw head was pointed to caudal trajectory (Fig. 2, 5). In the point of screw fractures morphology, the dynamic forces contributing the screw fracture were derived from hyperflexion of neck motion as Figure 5 indicated. This situation is also correlated with not following instructions of using Philadelphia brace to provide an optimal environment for bone fusion by restrict the range of neck movement.

Elliott et al. reviewed published series describing C1-2 posterior instrumented fusions with screw-rod constructs or transarticular screws and compared rates of fusion with and without postoperative external cervical orthoses ${ }^{3)}$. Online databases were searched and all including studies provided class III evidence, and no studies directly compared outcomes with 
or without external cervical orthoses use. There was no significant difference in the proportion of patients who achieved successful fusion between patients treated with external cervical orthoses and without external cervical orthoses for C1-2 posterior instrumented fusion patients. The estimates fusion rates were $97.4 \%$ with external cervical orthoses use and 97.9\% without external cervical orthoses use for screw-rod constructs. So, they concluded that external cervical orthoses may be unnecessary after C1-2 fusion with modern instrumentation, and recommended prospective, randomized studies with validated radiographic and clinical outcome metrics are necessary to determine the utility of external cervical or- thoses. This meta-analysis by Elliott et al. is interesting; however, the external cervical orthoses are so effective that they can certainly assist inproviding an optimal environment for bone fusion. Indeed, this review compared the outcomes focusing only the fusion rate after C1-2 posterior instrumented fusions without considering the other complications such as screw fracture. So, the opponent proposed that the need for bone fusion in this mostmobile area of the spine is so important for the stabilization of the area and long-term results for the patient that we would certainly err in favor of external cervical orthoses ${ }^{10}$. Indeed, it is emphasized that internal fixation of posterior arthrodesis using tricorticated bone graft is important factor for successful bone fusion ${ }^{7}$. C1 lateral mass screw and C2 pedicle screw with polyaxial screw and rod system supplemented with miniplate for interlaminar fusion might be an efficient alternative method to treat various atlantoaxial instabilities ${ }^{22)}$.

The second operation was performed to stabilize the atlantoaxial instability after transpedicle screw fractures. The fractured particle inserted inside of $\mathrm{C} 2$ vertebrae could not remove. The operation was completed by longer $\mathrm{C} 1$ lateral mass screws and $\mathrm{C} 2$ translaminar screws fixation. C2 translaminar screws commonly used as an alternative or salvage technique because it offers biomechanical stability similar to that of other C2 fixation methods but with minimal risk to neural and vascular structures $^{3)}$. C1 lateral mass screws and C2 translaminar screws fixation is equivalent to $\mathrm{C} 1$ lateral mass screws and $\mathrm{C} 2$ pedicle screws fixation in flexion/extensionand anterior-posterior translation ${ }^{2,3,19)}$. Radiographically demonstrated bony fusion was reported from $91.7 \%$ to $97.6 \%$ in C2 translaminar screws fixation $^{3,19)}$. But, this presented patient couldn't achieve the bony fusion in imaging studies during 4 months follow-up period after second operation, nevertheless using the autogenous iliac crest graft. But, the dynamic simple radiographs were stable in flexion/extension view of cervical lateral radiographs, although the bony fusion was not satisfied (Fig. 6). The patient was also not satisfied to bony fusion and underwent reoperation in other hospital.

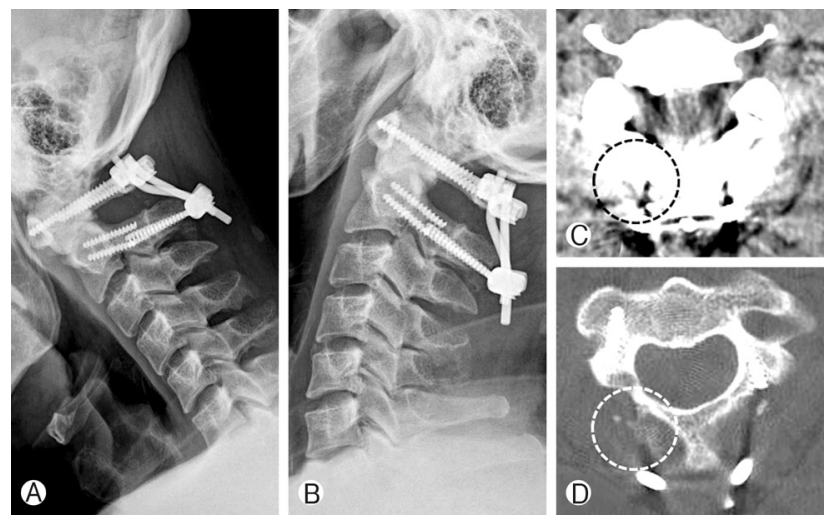

Fig. 6. Atlantoaxial spine was stable in flexion/extension lateral radiographs ( $A$ and $B$ ), But, the bony fusion was not satisfied ( $C$ and D)

Complications after operation were graded as minor, moderate, or major as classified by Rampersaud et al. ${ }^{20)}$. Minor complications required little (1 day) or no increase in the duration of stay with minimal or no additional treatment required. Moderate complications warranted treatment, increased the duration of stay by 2-7 days, and/or created no long-term sequelae ( $\leq 6$ months). Major complications required significant levels of treatment, increased the duration of stay by $>7$ days, and/or created longterms equelae ( $\geq 6$ months). In addition, these authors described an adverse event as any unexpected or undesirable incident happening as a result of surgery, either directly or indirectly. Thus, a complication can occur as a result of an adverse event, but it is also possible for an adverse event to happen without an associated complication. In this report, a patient with two-times repeated unlucky complication following atlantoaxial fusion was described; screw fracture and non bony union. This complication could include to unexpected and major compilations in classification by Rampersaud et al. ${ }^{20)}$. The authors considered that the first step of unfortunate clinical course is fail of neck immobilization during recovery period after atlantoaxial fixation. Some authors suggested that spine surgeons should reconsidered the use of bracing for C1-2 fusion procedures according to the bone fusion rate ${ }^{4)}$, but the authors want to emphasized this clinical failure without postoperative immobilization. To quote the appropriate saying, "A stitch in time saves nine."

\section{CONCLUSION}

Continuous complication after atlantoaixial fusion is rare, but the clinical course is unlucky to patients. This screw fractures could be happen without solid bone fusion by the overweight as lever function in Harms and Melcher methods 
which fixated the anterior column instability. Postoperative immobilization could provide important role to prevent the unintended clinical course of patients.

\section{REFERENCES}

1. Cho JH, Lee JK, Moon KS, Joo SP, Kim JH, Kim SH: Posterior arthrodesis in atlantoaxial instability: transarticular screw fixation vs wire fixation. Korean J Spine 3:9-15, 2006

2. Claybrooks R, Kayanja M, Milks R, Benzel E: Atlantoaxial fusion: a biomechanical analysis of two C1-C2 fusion techniques. Spine J 7:682-688, 2007

3. Dorward IG, Wright NM: Seven years of experience with C2 translaminar screw fixation: clinical series and review of the literature. Neurosurgery 68:1491-1499, 2011

4. Elliott RE, Tanweer O, Boah A, Morsi A, Ma T, FrempongBoadu A, et al: Is external cervical orthotic bracing necessary after posterior atlantoaxial fusion with modern instrumentation: meta-analysis and review of literature. World Neurosurg 79: 369-374, 2013

5. Elliott RE, Tanweer O, Boah A, Morsi A, Ma T, Smith ML, et al: Atlantoaxial fusion with screw-rod constructs: meta-analysis and review of literature. World Neurosurg, 2012 [Epub ahead of print]

6. Fehlings MG, Errico T, Cooper P, Benjamin V, DiBartolo T: Occipitocervical fusion with a five-millimeter malleable rod and segmental fixation. Neurosurgery 32:198-207, 1993

7. Finkemeier CG: Bone-grafting and bone-graft substitutes. J Bone Joint Surg Am 84:454-464, 2002

8. Finn MA, Apfelbaum RI: Atlantoaxial transarticular screw fixation: update on technique and outcomes in 269 patients. Neurosurgery 66:184-192, 2010

9. Gallie WE: Fractures and dislocations of the cervical spine. Am J Surg 46:495-499, 1939

10. Goel A, Kothari M: External cervical orthosis (ECO): to have or not to have. World Neurosurg 79:275-276, 2013
11. Goel A, Laheri V: Plate and screw fixation for atlantoaxial subluxation. Acta Neurochir (Wien) 129:47-53, 1994

12. Goldenberg D, Golz A, Joachims HZ: Retropharyngeal abscess: a clinical review. J Laryngol Otol 111:546-550, 1997

13. Harms J, Melcher RP: Posterior C1-C2 fusion with polyaxial screw and rod fixation. Spine (Phila Pa 1976) 26:2467-2471, 2001

14. Hott JS, Lynch JJ, Chamberlain RH, Sonntag VK, Crawford NR: Biomechanical comparison of C1-2 posterior fixation techniques. J Neurosurg Spine 2:175-181, 2005

15. Lall R, Patel NJ, Resnick DK: A review of complications associated with craniocervical fusion surgery. Neurosurgery 67: 1396-1402, 2010

16. Magerl F, Seemann PS: Stable posterior fusion of the atlas and axis by transarticular screw fixation. In: Kehr P, Weidner A (eds). Cervical Spine. I Springer-Verlag. Vienna, 1987, pp 322-327

17. Meyer B, Kuhlen D: Atlantoaxial fusion: Transarticular screws versus screw-rod constructs. World Neurosurg. 2012 [Epub ahead of print]

18. Mullett JH, McCarthy P, O’Keefe D, McCabe JP: Occipital fixation: effect of inner occipital protuberance alignment on screw position. J Spinal Disord 14:504-506, 2001

19. Park JS, Cho DC, Sung JK: Feasibility of C2 translaminar screw as an alternative or salvage of $\mathrm{C} 2$ pedicle screws in atlantoaxial instability. J Spinal Disord Tech 25:254-258, 2012

20. Rampersaud YR, Moro ER, Neary MA, White K, Lewis SJ, Massicotte EM, et al: Intraoperative adverse events and related postoperative complications in spine surgery: implications for enhancing patient safety founded on evidence-based protocols. Spine (Phila Pa 1976) 31:1503-1510, 2006

21. Ringel F, Reinke A, Stuer C, Meyer B, Stoffel M: Posterior C1-2 fusion with C1 lateral mass and C2 isthmic screws: accuracy of screw position, alignment and patient outcome. Acta Neurochir 154:305-312, 2012.

22. Yoon SM, Baek JW, Kim DH: Posterior atalntoaxial fusion with c1 lateral mass screw and c2 pedicle screw supplemented with miniplate fixation for interlaminar fusion: a preliminary report. J Korean Neurosurg Soc 52:120-125, 2012 